\title{
Border Molding-Teach Me What I am Blind to (Moffatt)
}

\author{
Mohammad Arif Lone* \\ Deportment of Dentistry, Sher-i-Kashmir Institute of Medical Sciences Bemina, India
}

Submission: May 09, 2017; Published: December 08, 2017

*Corresponding author: Mohammad Arif Lone, Deportment of Dentistry, Sher-i-Kashmir Institute of Medical Sciences Bemina, Srinagar Jammu \& Kashmir, India, Email: mohammadpgprostho@gmail.com

\begin{abstract}
Shaping or molding becomes necessary when something important is concerned, as it determines the value of the contents, like shaping of clay by a porter, shaping of student by a teacher, shaping of diversion of the road. The porter know what he wants to make out of the clay and gives it a required shape, likewise a teacher give shape to the thought and ideas of a student and a traffic divider signifies the importance of lane driving. Same way the prosthodontist knows the importance of the limiting structures of the oral cavity, which should be recorded with utmost care without interference during functional movements. Border molding (muscle trimming) an impression to adapt more closely to the tissues of the vestibule before securing the final impression is a time-honored procedure in prosthetic dentistry.
\end{abstract}

Keywords: Impression material; Border molding

\section{Opinion}

According to GPT-8, [1] Border molding is defined as "The shaping of the border area of an impression tray by functional or manual manipulation of the tissues adjacent to the borders to duplicate the contour and size of the vestibule or determining the extension of a prosthesis by using tissue function or manipulation of the tissues to shape the border area of an impression material."

The original material used for this purpose was modeling compound (Green Stick), which was introduced in 1907 by the Green brothers [2]. The technique of using impression compound for border molding is usually divided into steps, where sections of the border are molded in separate applications. Because of the number of insertions required, such a technique can be quite tedious and difficult. The technique of using modeling compound is difficult because the softened compound must be placed into the mouth without touching the lips, cheeks, or ridge. It retains its flow for very short period that if displaced it can lead to an inaccurate impression, if tissues are contacted before the tray is properly seated in the mouth for border molding. The other materials used for border molding have their advantages and limitations.

\section{Review Article}

A material which will allow simultaneous moldings of all borders has two general advantages

1. The number of insertions of the trays for maxillary and mandibular border molding could be reduced to two, a great time and motion advantage and

2. Development of all borders simultaneously avoids propagation of errors caused by a mistake in one section affecting the border contours in another section.

Ideal requirements of border molding material are:

A. Have sufficient body to allow it to remain in position on the borders during loading of the tray

B. Allow some preshaping of the form of the borders without adhering to the fingers

C. Have a setting time of 3 to 5 minutes

D. Retain adequate flow while seating in the mouth

E. Allow finger placement of the material into deficient parts after seating the Tray

F. Not cause excessive displacement of the tissues of the vestibule

G. Be readily trimmed and shaped so that excess material can be carved and the borders shaped before the final impression is made.

Hard acrylic resin and silicone materials have been used for this purpose, and both have serious deficiencies. Hard resins have 
a long setting time, do not attain proper consistency immediately after mixing, which requires a waiting time before insertion, and are difficult to trim. Also, if insertion is delayed too long, overextension will result. Heavy bodied silicone materials do not allow preshaping, placement into deficient spaces with a finger after insertion, and are difficult to trim after setting. Polyether impression materials meet all of the requirements previously listed. They can be shaped with a moist finger in or outside the mouth, and can be trimmed with a scalpel or a bur.

\section{Technique}

To make a snap impression of the oral cavity for the purpose of customized impression tray, the oral cavity is observed visually for height and width of the vestibular space. The patient is asked to open the mouth midway and the lips and cheeks are retracted very delicately to visualize the space available [3].

The impression is taken with the help of irreversible hydrocolloid material and a diagnostic casts is made in the usual manner. The diagnostic cast is inspected for undercuts, bony elevations, depressions and is relieved accordingly with the help of base plate wax, One thickness of base plate wax relief is provided over the crest of the ridge or both upper and lower casts and over the median raphae area of the palate. No relief is placed on the border areas except where undercuts are present.

A customized or special tray is constructed with autopolymerising acrylic resin or vacuum formed resin over the relieved diagnostic casts. To insert the tray within the oral cavity a handle is constructed on the anterior area while few dentists prefer three handles in the mandibular impression tray. These handles are made two in the molar region and one in the anterior area. The dimensions of the handle are $3-4 \mathrm{~mm}$ thick, $8 \mathrm{~mm}$ long and $8 \mathrm{~mm}$ high. Mark an outline of the impression tray on the cast with a pencil, the customized tray is $2 \mathrm{~mm}$ away from the vestibule so that it can be used to record the tissues during function with border molding material. The extensions of the customized impression tray are checked carefully intraoral. Further the extension of posterior palatal area can be confirmed with an indelible mark placed between hamular notches with midpoint approximately $2 \mathrm{~mm}$ distal to fovea palatine [4].

\section{Single Step Border Molding [5]}

Dispense a 3-inch strip of polyether material from the large tube onto a large mixing pad and add $21 / 2$ inches of catalyst from the small tube. Less catalyst is used than recommended is to provide sufficient working time to complete the border molding. Thoroughly mix the material for 30 to 40 seconds using a metal spatula. Apply tray adhesive material on the special tray before applying border molding material on it. After manipulation make a thin rope of polyether material and apply on the borders of the custom tray.

The material can be pre shaped with fingers moistened in cold water for proper contours. After shaping the impression tray is placed in the mouth, making certain to retract the lips sufficiently to avoid scraping the material from the borders. After placement in the oral cavity inspect all borders to make certain that impression material is present everywhere in the vestibule, if there is a deficient space anywhere transfer some materia1 from an adjacent site with a finger moistened in the patient's saliva. The patient can be immediately instructed to perform the border molding movements.

\section{Conventional Border Molding by Green Stick Compound [6]}

Border molding with the green stick has been recommended by Boucher, Tench and Kile. Modeling compounds are advantageous in many reasons as these materials soften quite easily and hard at mouth or room temperature. These can be reused and are cheap. The five main types of modeling compounds available in the market are differentiated by their color:
a. Brown (132-133 ${ }^{\circ} \mathrm{F}$ Working temperature)
b. White (132-134 ${ }^{\circ} \mathrm{F}$ Working temperature)
c. $\quad$ Black (132-134 ${ }^{\circ} \mathrm{F}$ Working temperature)
d. Gray (128-130 ${ }^{\circ} \mathrm{F}$ Working temperature)
e. Green (122-124 ${ }^{\circ} \mathrm{F}$ Working temperature)

Out of all these the green modelling compound is used for border molding as it has easy flow and good handling properties where as the brown modelling compound is mostly used for preliminary impression making.

The stick modelling compound is heated with flame from an alcohol air torch and is tempered with warm water $\left(60{ }^{\circ} \mathrm{C}\right)$ and placed with utmost care in the oral cavity while retracting the lips and cheeks carefully without touching. The tissues are recorded in functional form by molding the green stick to the form that is in harmony with the tissues. The molded tray is removed from the oral cavity and the green stick is immersed in the cold water to retain the form. The anterior area of the maxilla should be recorded first when the upper lip is elevated and extended outwards, downwards and inwards during this manipulation a $\mathrm{V}$ shaped notch should be recorded to accommodate the labial frenum (passive frenum without muscles) \& when Green stick compound comes in intimate contact to the tissues it leaves a dull surface. The buccal area of the maxilla should be recorded next from one side followed by the other.

During recording of the buccal vestibule the buccal frenum should be given due care as it is an active frenum and the muscles attached with it have functional influence of the function of the denture. The area can be recorded by manipulating the tissues in outward, downward and inward and forward and backward movement. Due to movement of mandible in the horizontal plane it is important to record the impression of coronoid notch on the disto buccal area of maxillary arch by doing sideways movement of the mandible, so a mild depression can be recorded in disto buccal area of the border molded impression. 
The posterior extension of the tray is border molded by palpating the hamular notches from both sides that can be felt with the help of $\mathrm{T}$ burnisher a $\mathrm{V}$ shaped instrument that engages the hamular notch followed by observing the post palatal area by asking the patient to say ah in a series of short both the areas is lined with indelible pencil. It is imperative to find the proper extension of the impression tray in the post palatal area as the there is no wall unlike the labial and buccal flange. The acrylic tray is marked with a different color indelible pencil and the tray is placed in the mouth.

Both the markings of the tray and the mouth should superimpose on each other signifying that the borders of the tray are accurate. Overextension or under extension of the tray should be corrected by using a guide of hamular notches and approximately $2 \mathrm{~mm}$ posteriorly to vibrating line. The added material of green stick will form a Cupid's bow shape after recording as it resembles the underlying shape of the posterior nasal spine of the maxilla. The functional recording of the mandible is even more time consuming and is dependent on what eyes can see, what the imagination can surmise and upon the influence of the adjacent muscles on the functional borders during manipulation. Blanchard has rightly said that "eyes in the fingers" help to locate what can't be seen during border molding, meaning to say that the palpation within mouth with the pulp of the finger after border molding when tray is inserted can guide the operator the extent of the tray [7].

Border molding the mandible is done starting with the anterior region by pulling the lip outwards, upwards and inwards, no side to side movement is recommended here as the lip does not from side to side during function. The cheek area is recorded by lifting the cheek outward, upward, inward, backward and forward to generate the movement of lower buccal frenum and the posterior most area is recorded by moving the area outward, upward, inward.

The lingual area is recorded next and it is the area that is more precise as the tongue musculature will have significant influence of the border. The lingual flange comprises the alveolingual sulcus which extends from the lingual frenum to the retromylohyoid curtain. The alveolingual sulcus has three main region are anterior, middle and posterior the region is recorded by placing the tray is in the mouth and the patient is asked to protrude the tongue followed by pushing against the anterior part of the palate that will determine the length and thickness respectively. The lingual flange is short anteriorly than posteriorly.

Premylohyoid prominence can be recorded in the canine premolar region as it corresponds to the Premylohyoid fossa while the molar region from Premylohyoid to Postmylohyoid eminence is recorded by asking the patient to protrude the tongue, this will generate the curvature of lingual flange in molar region. While the posterior most part of the lingual flange should extend $1 \mathrm{~cm}$ distal to the mylohyoid ridge. The mylohyoid ridge extends obliquely from the near crest in the molar region to end in the inferior border of the mandible. The posterior most part is influenced by superior constrictor and the medial pterygoid muscles which can be recorded by asking the patient to protrude the tongue followed by closing the mouth. This initiates the action of medial pterygoid muscles on the superior constrictor and defining the extension of the flange in the posterior most part and leads to recording of masseteric notch [8].

\section{Non Conventional Material Used for Border Molding $[2,3,9]$}

Border molding the custom tray is very important and can also be done by material other than green stick like autopolymerising acrylic resins, metallic pastes, elastomers \& impression waxes. Various attempts have been made to produce acrylic material that could be added to the tray for border molding without heat formation. These are the same methacrylate resin material with changed physical properties. The main disadvantage of the resin material is the leaching out of heat and monomer during the procedure. Other limitation associated with resin material is that they should be removed from the mouth before final hardening to avoid locking in the undercuts and removing in the early stage of hardening will result into distortion and after hardening further the material is to be finished and polished with burs and buff. So over all it is a time consuming and an easier said than done procedure.

Metallic oxide like zinc oxide eugenol paste can be used for border molding the tray. Equal quantities of the material are dispensed on the paper pad from both the tubes of base and catalyst and mixed following by rolling the material into a rope shape and applying on the borders of the tray for recording the tissues in the functional condition. The main limitation of the material is that zinc oxide eugenol can be irritating to the patient and once set is hard enough and can't be retracted from the undercuts. Utmost care is required to get the proper body of the material that can sustain itself and can be molded properly. Impression waxes can also be used to record the borders of the tray. Tilton used waxes to record the borders after making impression with compound while Knap used Adaptol wax for border molding. Wax has nearly all the qualities required for a good border molding material but the limitations are it becomes hard once set so can't be removed from undercuts. Wax is sticky so petroleum jelly must be applied on the operator hands and patients mouth. Wax also does not have enough strength and is brittle may flake once chilled.

\section{References}

1. Glossary of Prosthodontic terms.

2. Levin Bernard (1984) impression for complete dentures. Chicago quintessence publishing, USA, pp. 1-223.

3. Christenson GJ (1984) Impression materials for complete and partial denture Prosthodontics. Dent Clin Noth Am 28(2): 223-237.

4. Devan MM (1952) Basic principles of impression making. J Prosthet Dent 93(6): 503-508. 
5. Smith DE, Toolson LB, Bolender CL, James L Lord (1979) one step border molding of complete denture impression using a polyether impression material. J Prosthet Dent 41(3): 347-351.

6. Hickey JC, Zarb GA, Bolender CL (1985) Bouchers Prosthodontic treatment for edentulous patients, $9^{\text {th }}(\mathrm{edn})$, CV Mosby, St Louis, USA.

7. Blanchard EH (1952) Eyes in your finger. J Prsothet dent 2: 36-39.
8. Klein IE, Broner AS (1985) Complete denture second impression technique to minimise distortion of ridge and border tissues. J Prosthet Dent 54(5): 660-664.

9. Winkler S (2009) Essentials of complete denture Prosthodontics Second Edition.

\section{Your next submission with Juniper Publishers} will reach you the below assets

- Quality Editorial service

- Swift Peer Review

- Reprints availability

- E-prints Service

- Manuscript Podcast for convenient understanding

- Global attainment for your research

- Manuscript accessibility in different formats

( Pdf, E-pub, Full Text, Audio)

- Unceasing customer service

Track the below URL for one-step submission https://juniperpublishers.com/online-submission.php 